\title{
Perancangan Pemberian Pakan Ikan Otomatis Berbasis Arduino Dengan Indikator SMS
}

\author{
Rifqi Andreyanto ${ }^{1)}$, Andre Mochammad Satrio ${ }^{2)}$, M. Mujirudinn ${ }^{3)}$, Dwi Astuti Cahyasiwi ${ }^{4)}$ \\ Program Studi Teknik Elektro, Fakults Teknik \\ Universitas Muhammadiyah Prof. Dr. HAMKA \\ Jalan Tanah Merdeka No 6, Kp Rambutan, Jakarta, Indonesia \\ Telp: +62-21-8400341, Faks: +62-21-8411531 \\ Email: rifqi.andreyanto@yahoo.com, andremochammadsatrio81@gmail.com, mujirudin@uhamka.ac.id, \\ dwi.cahyasiwi@uhamka.ac.id
}

\begin{abstract}
Abstrak - Makalah ini membahas tentang pemberian pakan ikan yang dilakukan secara otomatis dengan mikrokontroler arduino uno. Pemberian dilakukan dengan pengaturan waktu serta pemberitahuan status melalui pesan singkat atau SMS sebagai indikator untuk memonitor dari jarak jauh. Indikator lainnya adalah LCD, LED, dan Buzzer Metode pemberian pakan dikerjakan dengan jadwal yang telah ditentukan sesuai dengan perkembangan berat ikan. Alat pakan otomatis ini dapat mendeteksi bahwa pakan telah habis dengan menggunakan sensor LDR. Hasil penelitian menunjukkan bahwa pakan ikan otomatis ini mampu menampung pakan pada wadahnya sebanyak $3 \mathrm{~kg}$ serta pengeluaran pakan yang mempunyai kesalahan atau error 0\%. Dapat mendeteksi pakan habis oleh sensor LDR apabila sisa pakan ikan tersisa sebanyak 20,5gram.
\end{abstract}

Kata kunci: Indikator, Mikrokontroler, Pakan Otomatis, Sensor LDR.

\begin{abstract}
Abstrak - This paper discusses the fish feed which is done automatically with an arduino uno microcontroller. Giving is done by setting the time and status notifications via short messages or SMS as indicators to monitor remotely. Other indicators are LCD, LED, and Buzzer. Feeding method is carried out with a predetermined schedule in accordance with the development of fish weight. This automatic feed tool can detect that the feed has been used up by using an LDR sensor. The results showed that this automatic fish feed is able to accommodate feed in its container as much as $3 \mathrm{~kg}$ as well as the expenditure of feed which has an error or error of 0\%. Can detect feed depleted by the LDR sensor if the remaining fish feed remains as much as $20.5 \mathrm{gram}$.
\end{abstract}

Keywords: Indicators, Microcontrollers, Automatic Feed, LDR Sensors

\section{Latar belakang}

Usaha peternakan ikan mempunyai prospek untuk dikembangkan karena tingginya permintaan akan produk peternakan ikan. Usaha peternakan ini juga memberi keuntungan yang cukup tinggi dan menjadi sumber pendapatan bagi banyak masyarakat di perdesaaan ataupun di perkotaan Indonesia.

Secara makro ekonomi, data Badan Pusat Statistik (BPS) mencatat pertumbuhan Produk Domestik Bruto (PDB) Nasional sektor perikanan pada tahun 2017 sebesar $6,75 \%$ atau naik sebesar 31\% dari tahun 2016. Angka PDB tersebut tercacat paling progresif dan berada diatas rata-rata pertumbuhan PDB Nasional yang hanya 5,03\%. Kinerja PDB Sektor perikanan, ditopang oleh volume produksi perikanan budidaya, dalam 5 (lima) tahun terakhir (20132017) tercatat tumbuh rata-rata sebesar $5,11 \%$, dimana pada tahun 2017 angka sementara volume produksi perikanan budidaya mencapai 16,16 juta ton [1].

Kemudian dengan memanfaatkan perkembangan teknologi di dalam peternakan ikan sangat membantu dalam meningkatkan produk maupun dapat mempermudah dalam pembudidayaannya. Salah satu penunjang keberhasilan produksi para peternak ikan adalah penggunaan teknologi tepat guna.

Kemajuan teknologi yang sedang berkembang saat ini adalah mikrokontroler salah satunya diberi nama Arduino. Arduino menyatakan perangkat lunak dan perangkat keras yang ditujukan untuk memudahkan siapa saja agar dapat membuat proyek-proyek elektronika dengan mudah dan cepat. Penerapan teknologi berupa alat bantu bagi para peternak ikan untuk mencapai efisiensi pekerjaan, antara lain pada bidang pemberian pakan. Pemberian pakan secara manual banyak menguras tenaga, waktu, dan materi yang terbuang percuma.

Dari permasalahan tersebut maka dibutuhkan suatu alat yang dapat memberi makan ikan secara otomatis, yang mampu melakukan pemberian pakan ikan secara otomatis pada waktuwaktu yang telah ditentukan yaitu dengan mengatur waktu pemberian pakan sesuai dengan jadwal yang diinginkan pengguna serta linier dalam pengeluaran pakan, 
artinya tidak berlebih dan tidak kekurangan sehingga tidak terjadi kesalahan dalam pemberian pakan ikan.

Banyak penelitian yang sebelumnya sudah melakukan metode pemberian pakan ikan otomatis diantaranya seperti penelitian dari Lukman Nulhakim yang berjudul "Alat Pemberi Makan Ikan di Akuarium Otomatis Berbasis Mikrokontroler ATMEGA 16" [2]. Penelitian yang dilakukan menggunakan Mikrokontroler AT89251 sebagai pengendali, memiliki sensor photo dioda, selain itu juga menggunakan LCD, LED sebagai indikator dan driver sebagai mengatur buka tutup selenoid pada pemberi pakan ikan otmatis. Kekurangan pada penelitian tersebut adalah hanya dapat digunakan pada kolam atau akuarium tertentu dan pengeluaran pakan yang belum linier

Selanjutnya penelitian dari Astriani Romaria Saragih yang berjudul "Rancang Bangun Perangkat Pemberi Pakan Ikan Otomatis Pada Kolam Pembenihan Ikan Berbasis Arduino" [3]. Penelitian yang dilakukan menggunakan Arduino Uno ATmega328, Motor Servo sebagai pembuka penutup pakan, Sensor LDR untuk mengetahui pakan sudah habis, LED, dan Buzzer sebagai tanda bahwa pakan sudah habis. Kekurangan dari penelitian tersebut adalah bahwa tempat pakan tidak ada penutup atau atap dan tidak menggunakan komponen RTC sebagai penjadwal waktu pemberian pakan.

Maka pakan ikan otomatis yang akan dirancang difasilitasi dengan beberapa indikator berupa LCD, LED, buzzer dan menggunakan SMS sebagai tanda bahwa pakan ikan telah habis dan pakan ikan sudah di berikan oleh alat tersebut. Kemudian menggunakan motor DC sebagai penggerak pakan sehingga pakan yang diberikan merata dan digunakan penutup dari wadah pakan yang akan dirancang. Alat ini sudah memiliki penutup pakan dan pengeluaran pakan yang linier atau tidak terjadi kelebihan atau kekurangan dalam pemberian pakan.

\section{Dasar Teori}

\subsection{Mikrokontroler}

Mikrokonroller adalah komputer yang berukuran mikro atau kecil dalam satu chip IC (Integrated Circuit) yang terdiri dari processor, memory, dan antarmuka yang dapat diprogram. Mikrokontroler di dalamnya terdapat IC atau chip dan terdiri dari CPU, memory, dan I/O yang bisa kita kontrol dengan memprogramnya. I/O (Input/Output) sering disebut dengan GPIO (General Purpose Input Output Pins) yang berarti pin yang bisa kita program sebagai input atau output sesuai kebutuhan [4].

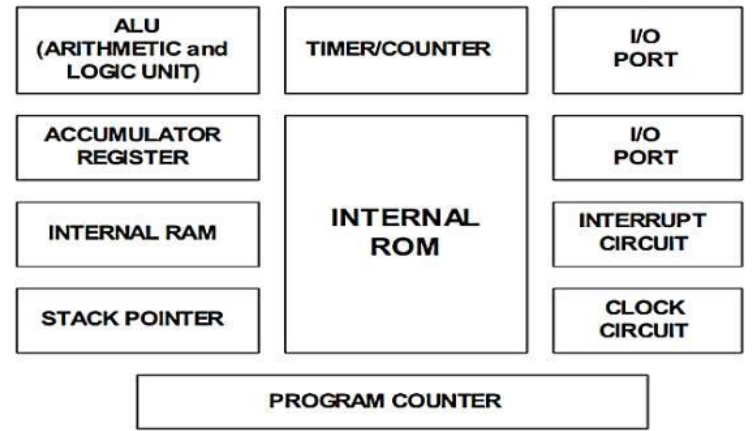

Gambar 1 Diagram Blok Mikrokontroler

Dengan kata lain mikrontroller alat elektronika yang mempunyai masukan dan keluaran serta kendali dengan program yang ditulis dan dihapus secara khusus. Mikrokontroller dapat kita gunakan untuk berbagai aplikasi misalnya untuk pengendalian, otomasi industri, akuisisi data, telekomunikasi, dan lain-lain. Penggerak pada mikrokontoler menggunakan bahasa pemograman assembly dengan berpatokan pada kaidah digital dasar sehingga pengoperasian sistem menjadi sangat mudah dikerjakan sesuai dengan logika sistem (bahasa assembly ini mudah dimengerti karena menggunakan bahasa assembly aplikasi dimana parameter input dan output langsung bisa diakses tanpa menggunakan banyak perintah).

\subsection{Catu Daya}

Catu daya merupakan pemberi sumber daya atau tegangan bagi perangkat elektronika lain. Perangkat elektronika mestinya dicatu oleh power supply DC yang stabil agar dapat dengan baik [2]. Secara umum istilah catu daya berarti suatu sistem penyearah-filter yang dapat merubah AC (arus bolakbalik) menjadi DC (arus searah) [4].

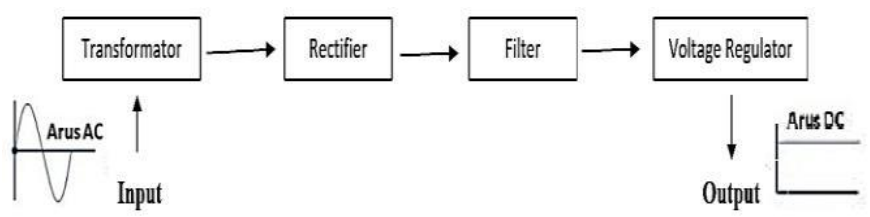

Gambar 2 Diagram Blok Catu Daya

\subsection{Sensor Cahaya (Photoresistor)}

Photoresistor atau LDR (Light Defendent Resistor) adalah komponen semikonduktor yang resistansinya dapat berkurang jika ada cahaya lebih terang yang jatuh di atasnya. Berfungsi untuk merubah besaran cahaya menjadi besaran listrik. Dalam kondisi gelap, resistansi LDR dapat mencapai $10 \mathrm{M}$ ohm, tapi pada saat kondisi terang, resistansi LDR turun hingga $1 \mathrm{~K}$ ohm bahkan bisa kecil lagi.

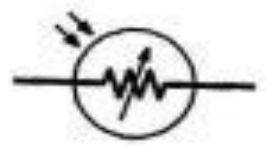

Gambar 3 Photoresistor 


\subsection{Motor Servo}

Motor servo adalah sebuah aktuator yang dapat bergerak dalam poros dan mempunyai spesifikasi untuk mengontrol posisi sudut yang presisi. Motor servo ada yang dikontrol secara serial ataupun dengan PWM (Pulse Width Modulation). PWM harus diatur agar memenuhi standar sinyal input sehingga motor servo dapat bergerak sesuai dengan perintah yang kita kirimkan lewat PWM [5].

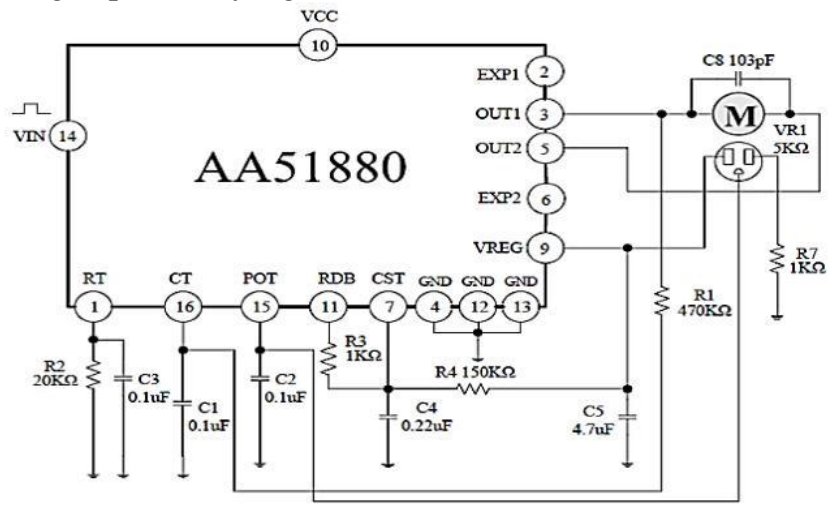

Gambar 4 Skematik Motor Servo [6]

\subsection{Indikator}

Indikator adalah variabel kendali yang dapat digunakan untuk mengukur perubahan yang terjadi pada sebuah kejadian ataupun kegiatan. Indikator juga dapat diartikan sebagai setiap ciri, karakteristik atau ukuran yang bisa menunjukkan perubahan yang terjadi pada sebuah bidang tertentu. Indikator bisa digunakan untuk mengevaluasi keadaan atau kemungkinan dilakukan pengukuran terhadap perubahan-perubahan yang terjadi dari waktu ke waktu. Dari penjelasan tersebut, bahwa penelitian ini memiliki beberapa indikator diantaranya menggunakan komponen LED, LCD, Buzzer, Modul GSM dan dijelaskan seperti subbab berikut ini.

\section{a. LED (Light Emitting Diode)}

Light Emitting Diode (LED) adalah komponen elektronika yang dapat memancarkan cahaya [5]. LED merupakan salah satu jenis diode yang hanya dapat mengalirkan arus listrik satu arah. Arus listrik hanya mengalir kalau tegangan positif dihubungkan ke kaki yang disebut anode dan tegangan negatif dihubungkan ke kaki yang dinamakan katode.

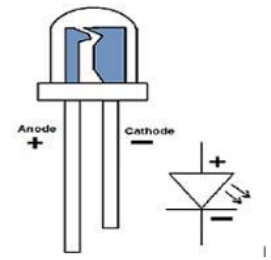

Gambar 5 LED

\section{b. LCD (Liquid Crystal Display)}

LCD merupakan singkatan dari Liquid Crystal Display. LCD bisa untuk menampilkan huruf dan angka, bahkan ada yang bisa untuk menampilkan gambar [4]. LCD ini berukuran 16x2 (2 baris 16 kolom) yang cukup untuk menampilkan informasi suhu atau informasi yang tidak terlalu panjang, sesuai dengan perintah program.

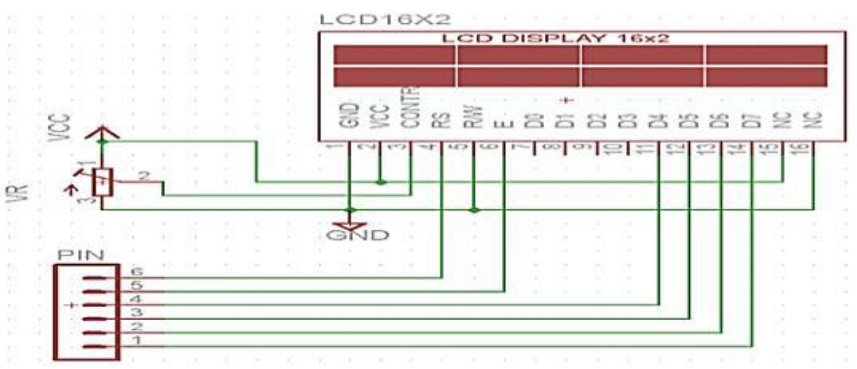

Gambar 6 Skematik Rangkaian LCD 16x2

\section{c. Serial Komunikasi 12C (Inter Integrated Circuit)}

I2C merupakan modul LCD yang dikendalikan secara serial sinkron dengan protocol I2C/IIC (Inter Integreted Circuit) atau TWI (Two Wire Interface). Modul I2C bekerja layaknya register sehingga dapat menghemat digital pin output pada mikrokontroler. Modul I2C berfungsi sebagai converter yang menggunakan chip IC PCF8574. IC ini memiliki 8 bit I/O expander untuk I2C bus yang pada dasarnya adalah sebuah shift register.

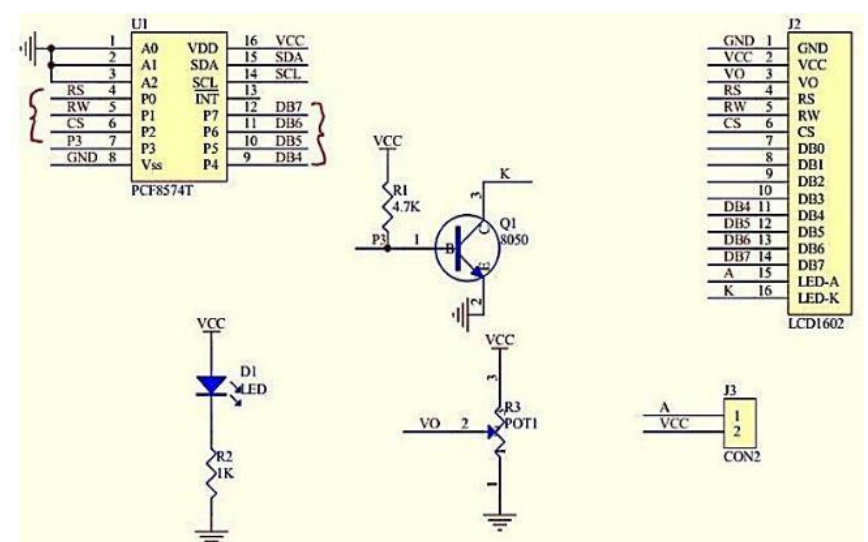

Gambar 7 Skematik Rangkaian 12C [6]

\section{d. Buzzer}

Buzzer adalah komponen yang merubah besaran elektrik menjadi besaran suara. Penggunaan bazzer untuk anatarmuka mikrokontroler sama prinsipnya dengan LED [5]. Pada dasarnya prinsip kerja buzzer hampir sama dengan loud speaker, dan terdiri dari kumparan yang terpasang pada diafragma, kemudian kumparan tersebut dialiri arus sehingga menjadi elektromagnet. Buzzer terbuat dari rangkaian piezo elektrik, yang bergetar dan menimbulkan suara ketika diberi tegangan DC pada kedua kutubnya. 


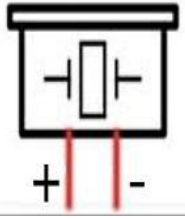

Gambar 8 Skematik Buzzer

\section{e. USART (Universal Synchronous - Asynchronous Receiver/Transmitter)}

USART merupakan komunikasi yang memiliki fleksibilitas tinggi, yang dapat digunakan untuk melakukan transfer data baik antar mikrokontroler maupun dengan modul-modul eksternal termasuk PC yang memiliki fitur UART. Universal sinkron / pemancar (USART) adalah jenis perangkat keras komunikasi yang memungkinkan komputer untuk berkomunikasi serentak dan asynchronous dengan perangkat yang terhubung secara serial. Sebuah USART memberikan seri komunikasi data dari port serial dan lebih dari RS 232 protokol standar [5].

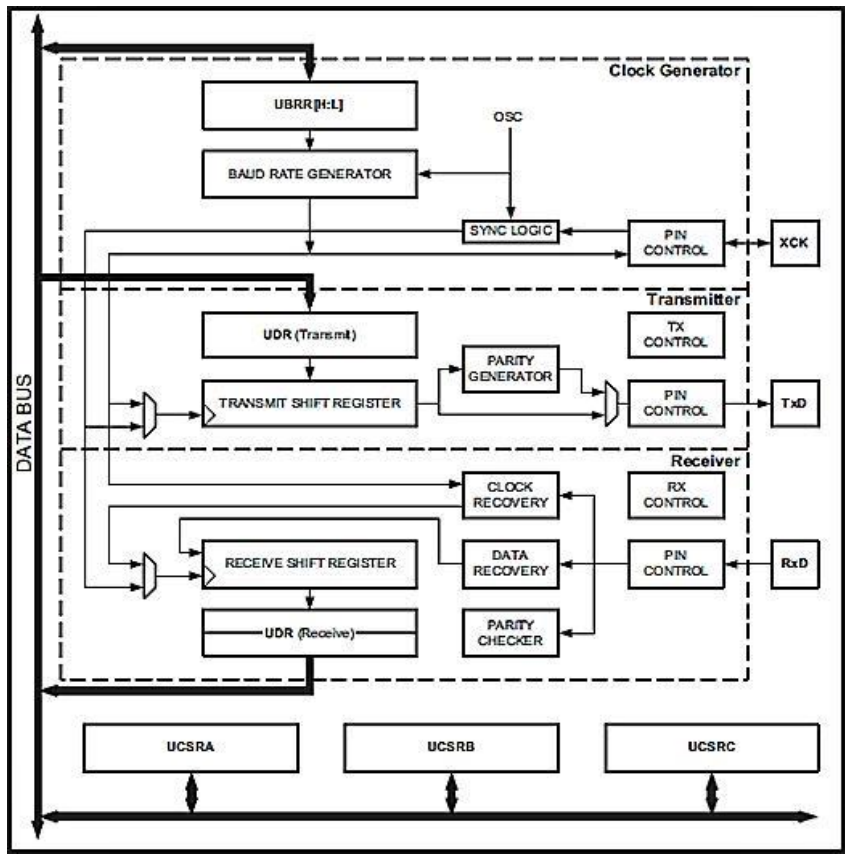

Gambar 9 Diagram Blok USART

\subsection{Time atau Counter}

Timerl Counter adalah seperangkat pencacah biner (binary counter) yang terhubung ke saluran data mikrokontroler, sehingga mikrokontroler bisa membaca kondisi pencacah dan jika diperlukan mikrokontroler dapat pula merubah kondisi pencacah tersebut. Saat sinyal clock yang diberikan sudah melebihi kapasitas pencacah, maka pencacah akan memberikan sinyal overflow/ limpahan. Limpahan pencacah ini dicatat dalam suatu register. Timer pada dasarnya hanya menghitung pulsa clock. Frequensi pulsa clock yang dihitung tersebut sama dengan frequensi kristal yang dipasanga tau dapat diperlambat menggunakan prescaler dengan faktor 8, 64, 256 atau 1024 [5].

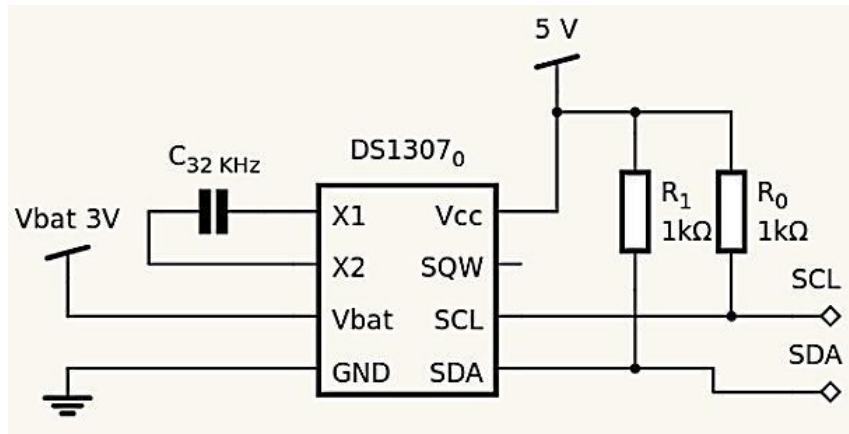

Gambar 10 Skematik Modul RTC

\section{Perancangan Sistem}

\subsection{Kerangka Perancangan}

Dalam melakukan suatu perancangan harus memiliki proses dan langkah-langkah yang digunakan. Proses dan langkah-langkah perancangan dalam tugas akhir ini dapat dilihat pada gambar dibawah ini.

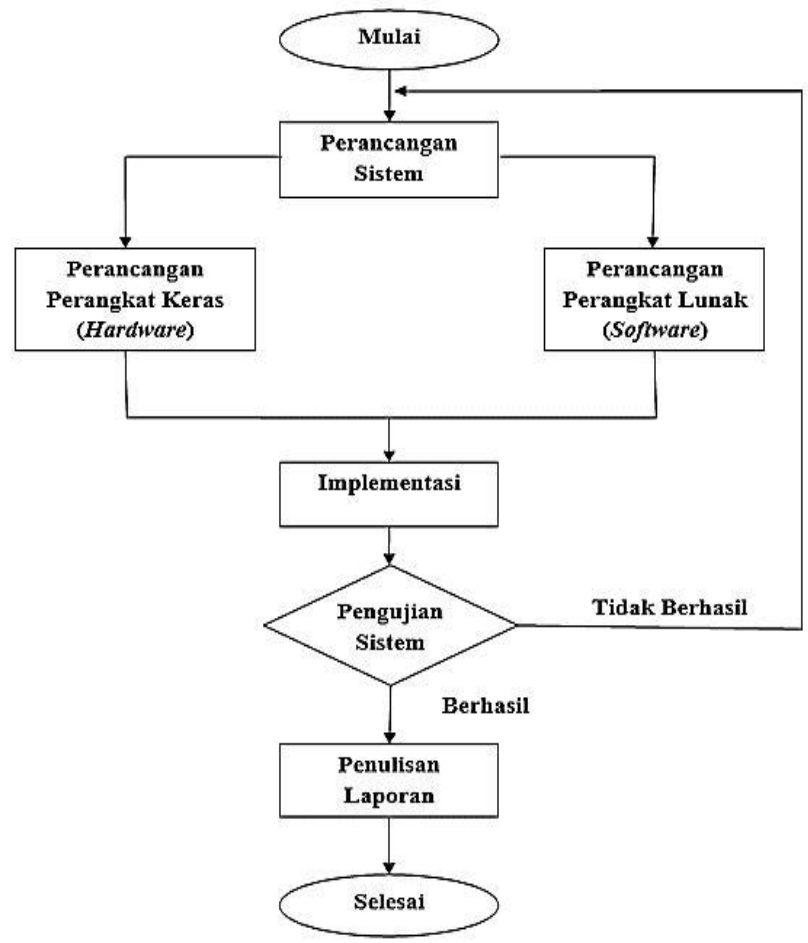

Gambar 11 Kerangka Perancangan Pakan Ikan Otomatis

\subsection{Perancangan Perangkat Keras (Hardware)}

Pada perancangan perangkat keras (Hardware) ini terdiri dari beberapa perancangan seperti perancangan pakan ikan, rangkaian catu daya, motor servo, Real Time Clock (RTC), Liquid Crystal Display (LCD), sensor LDR, modul GSM, Light Emmiting Diode (LED) dan dapat dilihat pada gambar berikut. 


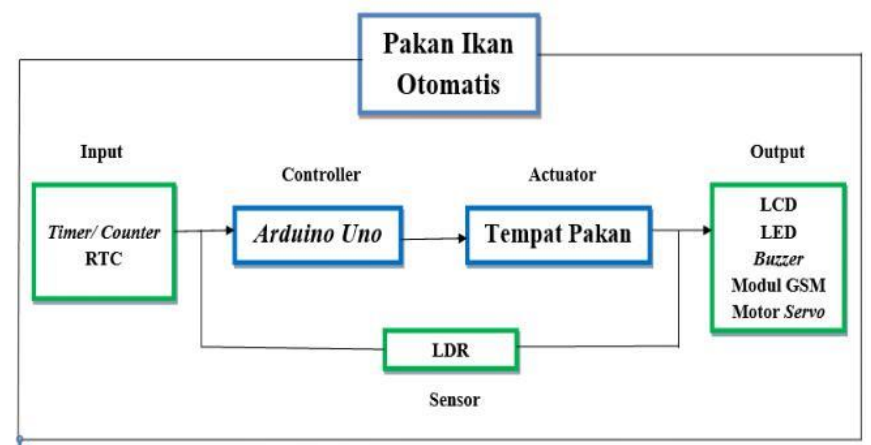

Gambar 12 Diagram Blok Perancangan Pakan Ikan Otomatis

Berdasarkan diagram blok diatas prinsip kerja dari alat ini, yaitu ketika catu daya diaktifkan maka Arduino UNO (Pengendali), RTC, motor servo, sensor LDR, modul GSM, Buzzer, dan LCD akan aktif. RTC ds1307 disetting sesuai dengan jam atau waktu nyata dengan menggunakan Arduino UNO, setelah settingan waktu selesai maka pada LCD akan di tampilkan berupa waktu dan tanggal, bulan dan tahun. Pemberian pakan ikan diberikan 3 kali sehari yaitu pukul 09.00 WIB, 15.00 WIB, dan 21.00 WIB. Jika pada LCD tersebut waktu menunjukkan pukul $09.00 \mathrm{WIB}, 15.00 \mathrm{WIB}$ dan 21.00 WIB maka motor servo akan aktif, tuas pada motor servo akan bergerak yang membuat pakan ikan terjatuh kekolam dengan tempat pakan yang telah dilubangi.

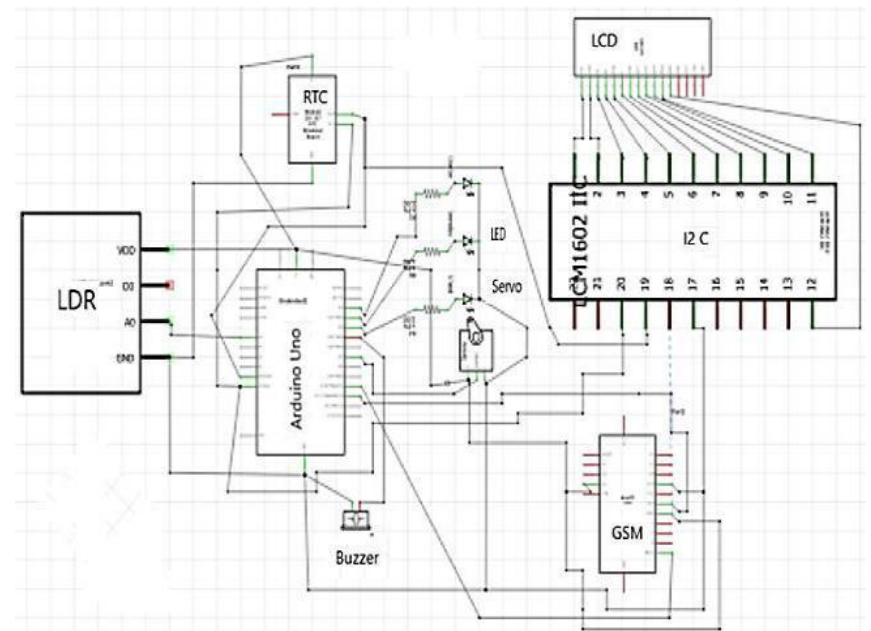

Gambar 13 Skematik Rangkaian Keseluruhan

Pemberian makan ikan yang dilakukan oleh motor servo yaitu selama beberapa detik atau menit, disesuai kan dengan pertumbuhan ikan yang dipelihara atau diternak. Sensor LDR akan mendeteksi kalau pakan habis, jika pakan masih ada maka LDR akan terhalang dari cahaya yang diterimanya. Jika LDR mendeteksi pakan habis maka akan ditampilkan pada LCD informasi berupa "Pakan Telah Habis, Segera Di Isi", dan "Pakan Aman" apabila tempat pakan terisi makanan ikan.

Selain itu juga akan diberitahu peringatan menggunakan buzzer yang akan berbunyi jika pakan tersebut habis. Kemudian fungsi LED akan membaca berwarna hijau apabila pakan ikan telah aktif dan berwarna merah jika pakan ikan telah habis. Kegunaan modul GSM untuk memberi tahu dan menyampaikan ke Handphone pengguna atau si peternak bahwa 'Pakan Telah Habis, Segera Di Isi', dan "Pakan Telah Diberikan".

\subsection{Perancangan Perangkat Lunak (Software)}

Perangkat lunak yang dirancang menggunakan aplikasi arduino IDE pada laptop atau komputer dengan bahasa C untuk memberikan gambaran umum jalannya program dan memudahkan pembuatan perangkat lunak, maka dibuat diagram alir yang menunjukkan jalannya program. Perangkat lunak ini disusun untuk mengatur kinerja keseluruhan dari sistem yang terdiri dari beberapa perangkat keras yang telah ditentukan agar sistem dapat berjalan dengan baik.

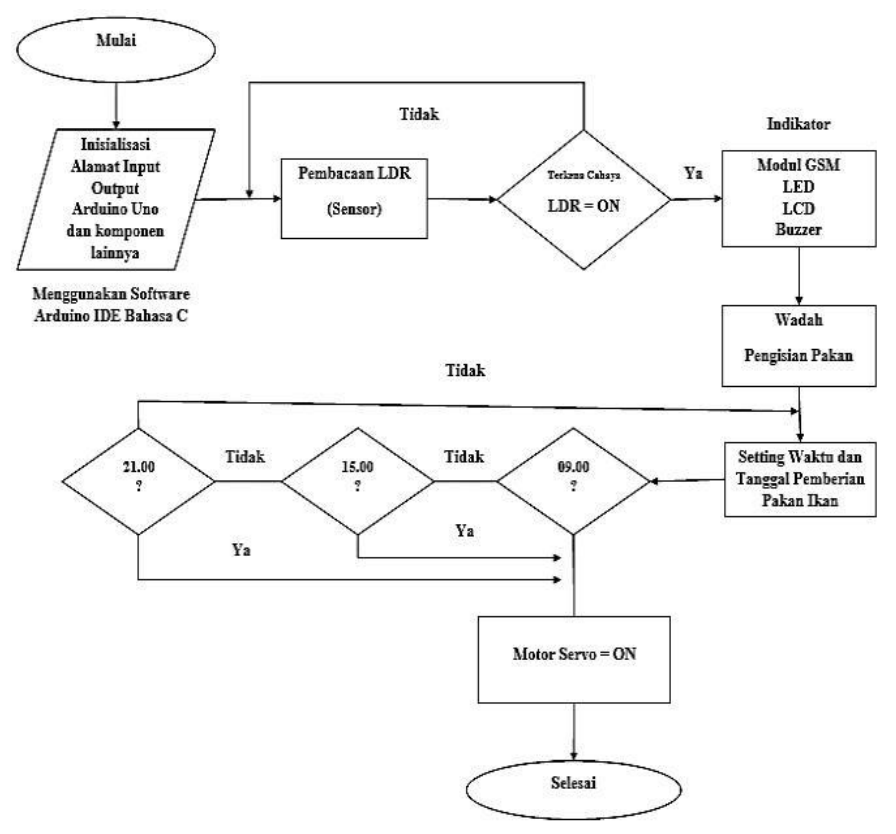

Gambar 14 Diagram Alir Kerja Pakan Ikan Otomatis

\section{Hasil Perancangan dan Pembahasan}

\subsection{Hasil Perancangan}

Pada gambar 15 merupakan hasil dari perancangan pakan ikan otomatis. Terdiri dari tempat penampung pakan yang berbahan akrilik dengan ketebalan $2 \mathrm{~mm}$. Kemudian terdapat arduino, motor servo, buzzer, Modul GSM, RTC, LED, LCD, LDR dan breadboard sebagai penghubung arduino dengan komponen lainnya. Komponen - komponen tersebut diletakkan dibagian depan wadah penampung pakan. Alat ini dirancang sedemikian rupa dengan menggunakan bahan akrilik bening agar komponen tersebut mudah dilihat. 


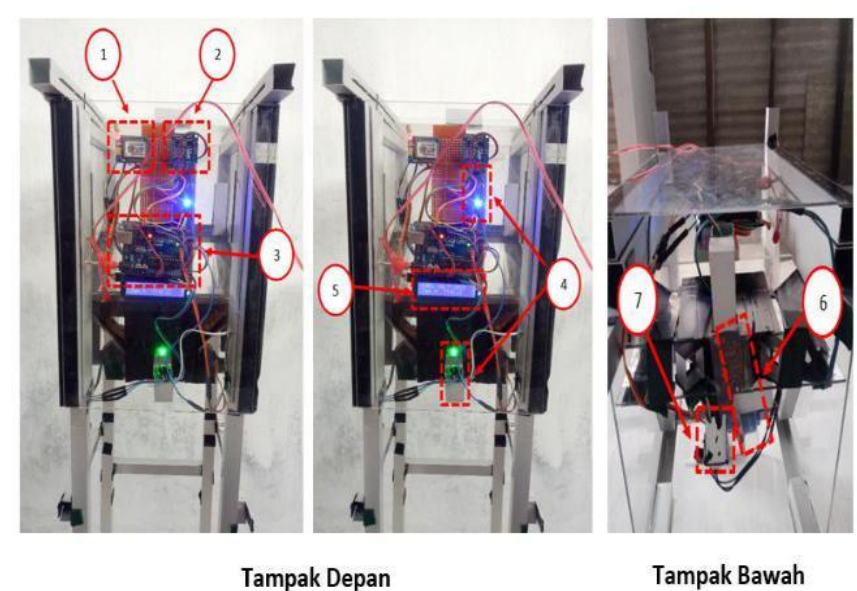

Gambar 15 Perancangan Pakan Ikan Otomatis

Keterangan :

1. Nomor merupakan Modul GSM

2. Nomor 2 merupakan RTC

3. Nomor 3 merupakan Arduino

4. Nomor 4 merupakan LED

5. Nomor 5 merupakan LCD

6. Nomor 6 merupakan Motor Servo

7. Nomor 7 merupakan Sensor Cahaya (LDR)

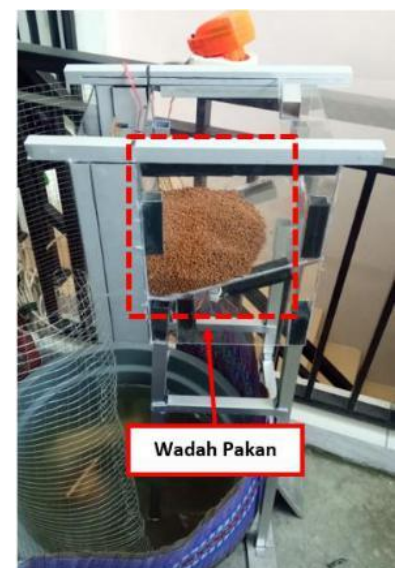

Gambar 16 Perancangan Pakan Ikan Otomatis Tampak Samping

Wadah dari tempat pakan ikan otomatis ini dapat menampung sebanyak $3 \mathrm{~kg}$ pelet ikan. LCD dapat menampilkan waktu dan mengetahui pakan telah habis kemudian modul gsm akan meneruskan untuk mengirimkan sms. Led akan menampilkan warna dan Buzzer akan berbunyi memberikan informasi yang dapat diketahui dengan program yang telah diatur sesuai dengan fungsinya. Terdapat tiang tiang disusun menggunakan bahan hollow alumunium dan menggunakan sumber tegangan sebesar $12 \mathrm{VDC}$ agar komponen yang disusun dapat bekerja dengan baik.

\subsection{Pembahasan}

Pada pembahasan ini untuk mengetahui permasalahan dengan pemecahan masalah yang dikaji. Dalam pembahasan ini dibagi menjadi 2 bagian yaitu pengujian fungsional dan pengamatan.

\subsubsection{Pengujian Fungsional}

a. Pengujian Catu Daya

Hasil pengukuran dari catu daya yang digunakan menghasilkan tegangan sebesar 12VDC. Tegangan tersebut relatif aman untuk digunakan karena untuk tegangan input pada mikrokontroler dapat digunakan sebesar 6-20 volt DC.

Tabel 1 Hasil pengujian catu daya

\begin{tabular}{ccc}
\hline Tegangan Input & Tegangan Output & Tegangan di Multimeter \\
\hline $220 \mathrm{VAC}$ & $12 \mathrm{VDC}$ & $12 \mathrm{VDC}$ \\
\hline
\end{tabular}

\section{b. Pengujian Mikrokontroler}

Pengujian ini dilakukan untuk mengetahui apakah dapat berfungsi dengan baik atau tidak. Pengujian ini dapat dilakukan dengan sederhana saja yaitu hanya menyambungkan kabel catu daya dengan konektor input tegangan pada mikrokontroler maka led indikator pada mikrokontroler tersebut akan menyala berwarna hijau dan dapat digunakan dengan mengupload program sederhana maka lampu led akan berkedip.

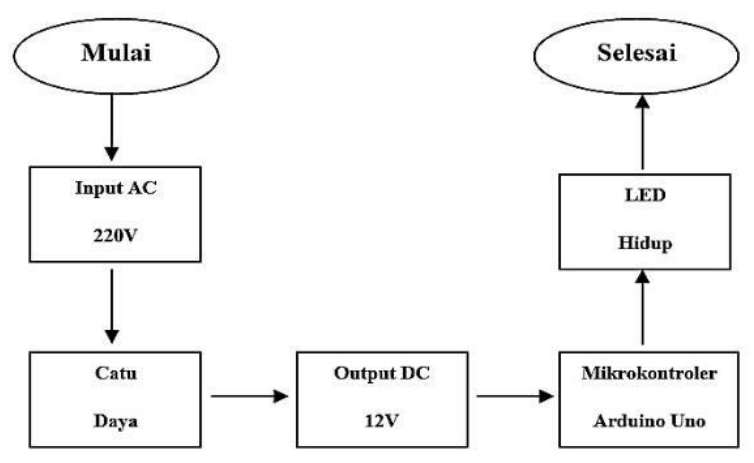

Gambar 17 Pengujian Mokrokontroler

\section{c. Pengujian LCD}

Pengujian ini dilakukan untuk mengetahui apa saja yang akan tampilkan pada layar LCD. Program yang di lakukan adalah menyesuaikan tampilan pada waktu seperti, hari, tanggal, bulan, tahun dan jam pada saat alat pakan bekerja. Apabila pakan habis maka LCD juga akan menampilkan Pakan Ikan Habis Segera Di Isi.

Tabel 2 Pengujian LCD

$$
\text { Pakan Habis }
$$
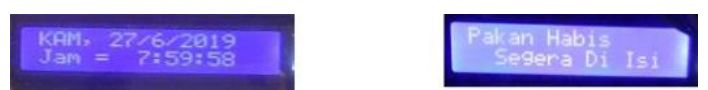


\section{d. Pengujian RTC}

Pengujian ini dilakukan untuk mengetahui apakah program yang digunakan pada RTC sesuai dengan waktu yang berjalan pada saat ini. Program yang dibuat adalah agar mengetahui hari, tanggal, bulan, tahun dan jam pada saat alat pakan bekerja.

Tabel 3 Pengujian RTC dengan waktu sesungguhnya

\begin{tabular}{|c|c|c|c|}
\hline Percobaan & $\begin{array}{l}\text { Waktu RTC } \\
\text { pada LCD }\end{array}$ & $\begin{array}{c}\text { Waktu } \\
\text { Sesungguhnya }\end{array}$ & $\begin{array}{l}\text { Selisih } \\
\text { Waktu }\end{array}$ \\
\hline 1 & $\begin{array}{c}\text { Kamis, } 11 \\
\text { Juli } 2019 \\
17: 01: 51\end{array}$ & $\begin{array}{c}\text { Kamis, 11 Juli } \\
2019 \\
17: 01: 51\end{array}$ & 00:00:00 \\
\hline 2 & $\begin{array}{l}\text { Kamis, } 11 \\
\text { Juli 2019 } \\
\text { 17:02:00 }\end{array}$ & $\begin{array}{c}\text { Kamis, } 11 \text { Juli } \\
\text { 2019 } \\
17: 02: 00\end{array}$ & 00:00:00 \\
\hline 3 & $\begin{array}{c}\text { Jum'at, } 12 \\
\text { Juli } 2019 \\
14: 40: 25\end{array}$ & $\begin{array}{c}\text { Jum'at, } 12 \\
\text { Juli 2019 } \\
14: 40: 25\end{array}$ & 00:00:00 \\
\hline 4 & $\begin{array}{c}\text { Jum'at, } 12 \\
\text { Juli 2019 } \\
\text { 14:41:07 }\end{array}$ & $\begin{array}{c}\text { Jum'at, } 12 \\
\text { Juli 2019 } \\
\text { 14:41:07 }\end{array}$ & 00:00:00 \\
\hline 5 & $\begin{array}{c}\text { Minggu, } 14 \\
\text { Juli 2019 } \\
06: 45: 17\end{array}$ & $\begin{array}{c}\text { Minggu, } 14 \\
\text { Juli } 2019 \\
06: 01: 13\end{array}$ & 00:00:04 \\
\hline 6 & $\begin{array}{c}\text { Minggu, } 14 \\
\text { Juli } 2019 \\
7: 22: 52\end{array}$ & $\begin{array}{c}\text { Minggu, } 14 \\
\text { Juli 2019 } \\
07: 22: 48\end{array}$ & 00:00:04 \\
\hline 7 & $\begin{array}{l}\text { Senin, } 15 \\
\text { Juli } 2019 \\
20: 15: 34\end{array}$ & $\begin{array}{c}\text { Senin, } 15 \text { Juli } \\
2019 \\
20: 15: 20\end{array}$ & 00:00:14 \\
\hline 8 & $\begin{array}{l}\text { Senin, } 15 \\
\text { Juli } 2019 \\
21: 13: 16\end{array}$ & $\begin{array}{c}\text { Senin, 15 Juli } \\
\text { 2019 } \\
21: 13: 02\end{array}$ & 00:00:14 \\
\hline 9 & $\begin{array}{c}\text { Selasa, } 16 \\
\text { Juli } 2019 \\
10: 08: 18\end{array}$ & $\begin{array}{c}\text { Selasa, } 16 \text { Juli } \\
2019 \\
10: 08: 00\end{array}$ & 00:00:18 \\
\hline 10 & $\begin{array}{l}\text { Selasa, } 16 \\
\text { Juli } 2019 \\
21: 31: 29\end{array}$ & $\begin{array}{c}\text { Selasa, 16 Juli } \\
2019 \\
21: 31: 05\end{array}$ & 00:00:19 \\
\hline
\end{tabular}

\section{e. Pengujian LDR}

Pengujian ini dilakukan untuk mengetahui apakah sensor LDR ini dapat mendeteksi cahaya sebagai saklar/ switch sehingga alat pakan otomatis tersebut dapat mengetahui kondisi bahwa tempat pakan ikan sudah habis dan harus segera di isi kembali. Maka LDR akan terhubung dengan beberapa indikator seperti Buzzer, modul GSM, LED dan LCD.

Tabel 4 Pengujian LDR

\begin{tabular}{|c|c|c|c|c|c|c|c|}
\hline \multirow[t]{2}{*}{ Cahaya } & Buzzer & \multicolumn{2}{|c|}{ SMS } & \multicolumn{2}{|r|}{ LED } & \multicolumn{2}{|c|}{ LCD } \\
\hline & HidupMati & $\begin{array}{l}\text { Terkiri } \\
\mathrm{m}\end{array}$ & $\begin{array}{c}\text { Tidak } \\
\text { Terkirim }\end{array}$ & Hijau & BiruMerah & $\underset{\mathrm{f}}{\text { Akti }}$ & Tidak \\
\hline & $\checkmark$ & $\checkmark$ & & $\checkmark$ & $\checkmark$ & $\checkmark$ & \\
\hline Terang & 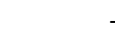 & & - & & - & & - \\
\hline Gelap & $\checkmark$ & - & - & $\checkmark$ & $\checkmark$ & - & - \\
\hline
\end{tabular}

\section{f. Pengujian Buzzer}

Pengujian ini dilakukan untuk mengetahui apakah buzzer dapat berfungis (hidup) atau tidak. Program diatur untuk menyesuaikan apabila pakan dinyatakan telah habis maka akan hidup. Buzzer tersebut akan berhenti berbunyi ketika pakan ikan telah terisi kembali.

Tabel 5 Pengujian Buzzer

\begin{tabular}{ccc}
\hline Percobaan & \multicolumn{2}{c}{ Buzzer } \\
& Hidup & Mati \\
\hline Pakan Terisi & - & $\checkmark$ \\
Pakan Habis & $\checkmark$ & - \\
\hline
\end{tabular}

\section{g. Pengujian LED}

Pengujian ini dilakukan untuk mengetahui bahwa led dapat bekerja dengan fungsinya atau tidak. Led terbagi menjadi 3 bagian yang memiliki fungsi yang berbeda. Dijelaskan bahwa pakan telah aktif berwarna hijau, pakan sedang terisi berwarna hijau dan pakan telah habis berwarna merah. Maka dapat dilihat dari tabel berikut.

Tabel 6 Pengujian LED

\begin{tabular}{cccc}
\hline Percobaan & \multicolumn{3}{c}{ LED } \\
\cline { 2 - 4 } & Hijau & Biru & Merah \\
\hline Pakan Aktif & $\checkmark$ & $\checkmark$ & - \\
Pakan Terisi & $\checkmark$ & $\checkmark$ & - \\
Pakan Habis & $\checkmark$ & & $\checkmark$ \\
\hline
\end{tabular}

\section{h. Pengujian Motor Servo}

Pengujian ini dilakukan untuk mengetahui bahwa motor dapat bekerja dengan baik atau tidak. Motor servo digunakan untuk membuka atau menutup pakan yang keluar. Motor servo diatur berdasarkan putaran sudut agar dapat membuka tempat penampung pakan dan ditetapkan oleh tiga waktu.

Tabel 7 Pengujian Motor Servo

\begin{tabular}{ccc}
\hline Waktu & \multicolumn{3}{c}{ Motor Servo } \\
\cline { 2 - 3 } & Hidup & Mati \\
\hline 09.00 & $\checkmark$ & - \\
15.00 & $\checkmark$ & - \\
21.00 & $\checkmark$ & - \\
\hline
\end{tabular}




\section{i. Pengujian Modul GSM}

Pengujian ini dilakukan untuk mengetahui bahwa modul gsm dapat bekerja sesuai fungsinya atau tidak. Modul gsm ini akan mengerim informasi berupa pesan singkat (SMS). Dijelaskan bahwa Modul GSM diatur menjadi 2 pesan singkat. Apabila pakan habis maka akan muncul sms berupa "Pakan Ikan Habis Segera Di Isi" dan "Pakan ikan telah di berikan" jika pakan telah diberikan. Kemudia dapat dilihat pada tabel berikut.

Tabel 8 Pengujian Modul GSM

\begin{tabular}{ccc}
\hline Percobaan & \multicolumn{2}{c}{ Modul GSM (SMS) } \\
\cline { 2 - 3 } & Terkirim & Tidak Terkirim \\
\hline Pakan Diberikan & $\checkmark$ & - \\
Pakan Habis & $\checkmark$ & -
\end{tabular}

\subsubsection{Pengamatan}

Pengamatan adalah kegiatan untuk mengetahui bahwa dalam perancangan pakan ikan otomatis bekerja secara keseluruhan dan agar mengetahui apa saja yang dapat mempengaruhi dalam pemberian pakan ikan tersebut.

\section{a. Pengamatan sensitivitas LDR terhadap sisa pakan}

Dalam pengamatan ini adalah untuk mengetahui bahwa sensor akan menyatakan habis apabila buzzer dan sms aktif. Maka dari itu perlu diketahui sensitivitas dari LDR tersebut dengan cara mengetahui sisa pakan yang tersisa, sehingga sensor tersebut akan aktif dan menyatakan bahwa pakan harus segera diisi.

Tabel 9 Pengamatan sensitivitas LDR terhadap sisa pakan

\begin{tabular}{cc}
\hline Percobaan & Sisa Pakan (gram) \\
\hline 1 & 21 \\
2 & 21 \\
3 & 21 \\
4 & 20 \\
5 & 21 \\
6 & 19 \\
7 & 20 \\
8 & 20 \\
9 & 21 \\
10 & 21 \\
\hline
\end{tabular}

Dari tabel 9 didapat hasil pengujian sensitivitas sensor LDR menyatakan bahwa akan mendeteksi habis ternyata menyisakan pakan dengan berat pakan sebesar 19gram sampai dengan 21 gram.

$$
\text { Rata-rata }=\frac{21+21+21+20+21+19+20}{+21+21=20,5 \mathrm{gr} 10}+20
$$

Maka di dapat rata-rata sebesar 20,5gr sisa pakan yang dapat dideteksi oleh sensor LDR dan dinyatakan habis.

\section{b. Pengamatan berat pakan yang dikeluarkan}

Dalam pengamatan ini adalah untuk mengetahui berat pakan yang dikeluarkan, sehingga pakan dapat menyesuaikan kondisi ikan. Apabila pakan yang keluar terlalu banyak dan terlalu sedikit maka tidak baik untuk perkembangan ikan dan dapat berdampak pada kolam ikan juga.

Tabel 10 Pengamatan berat pakan yang dikeluarkan

\begin{tabular}{ccccc}
\hline Percobaan & $\begin{array}{c}\text { Waktu Buka } \\
\text { Motor Servo } \\
(\mathrm{ms})\end{array}$ & $\begin{array}{c}\text { Sudut } \\
\text { Terukur }\end{array}$ & $\begin{array}{c}\text { Pakan Yang } \\
\text { dikeluarkan } \\
\text { (gram) }\end{array}$ & Error \\
\hline 1 & 100 & $15^{0}$ & 2 & $0 \%$ \\
2 & 150 & $20^{0}$ & 3 & $0 \%$ \\
3 & 180 & $25^{0}$ & 4 & $0 \%$ \\
4 & 200 & $25^{0}$ & 5 & $0 \%$ \\
\hline
\end{tabular}

Berdasarkan dari tabel 10 dapat dilihat terdapat 4 kali percobaan. Pertama pada waktu buka motor servo $100 \mathrm{~ms}$ dengan sudut $15^{0}$ pakan yang dikeluarkan rata-rata yaitu sebanyak 2gram dengan persentase kesalahan sebesar $0 \%$. Kedua pada waktu buka motor servo $150 \mathrm{~ms}$ dengan sudut $20^{0}$ pakan yang dikeluarkan rata-rata yaitu sebanyak 3 gram dengan persentase kesalahan sebesar $0 \%$.

Ketiga pada waktu buka motor servo $180 \mathrm{~ms}$ dengan sudut $25^{\circ}$ pakan yang dikeluarkan rata-rata yaitu sebanyak 4gram dengan persentase kesalahan sebesar $0 \%$. Keempat pada waktu buka motor servo $200 \mathrm{~ms}$ dengan sudut $25^{\circ}$ pakan yang dikeluarkan rata-rata yaitu sebanyak 5 gram dengan persentase kesalahan sebesar $0 \%$. Pada semua percobaan tersebut didapat rata rata error $0 \%$.

Berdasarkan pada gambar grafik 18 terhadap sudut yang diukur maka berat pakan yang dikeluar dari rentang 2gram sampai 5gram dan waktu buka motor servo dari rentang $100 \mathrm{~ms}$ sampai $200 \mathrm{~ms}$.

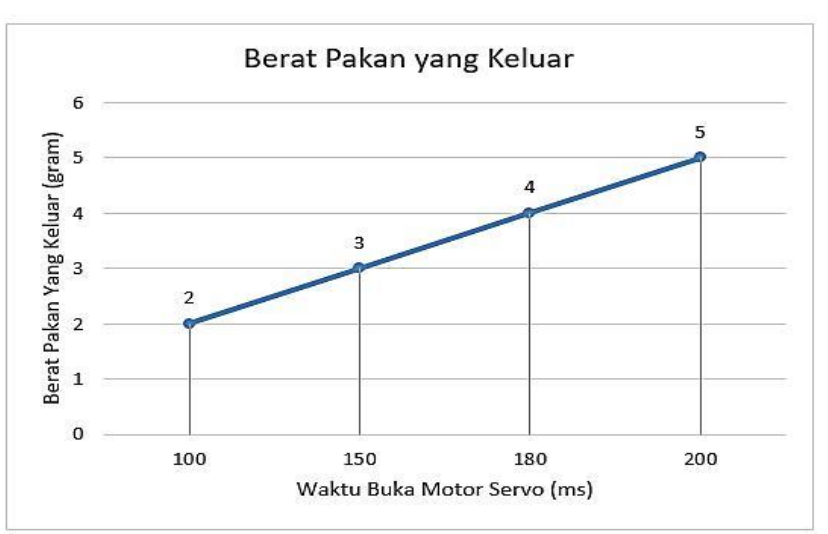

Gambar 18 Grafik Pengujian Berat Pakan yang Keluar 


\section{c. Pengamatan Indikator Harian}

Dalam pengamatan harian ini kita dapat mengetahui apakah perancangan pakan ikan keseluruhan dapat bekerja sesuai fungsinya atau tidak. Maka dari itu dapat diketahui dengan beberapa indikator yang tersedia. Informasi yang dikirim sebagai acuan sehingga kita mengetahui bahwa pakan telah habis dan telah diberikan.

$>$ Minggu Pertama

Pada minggu pertama dimulai hari kamis, 27 Juni 2019 sampai dengan hari rabu, 3 Juli 2019. Percobaan ini dilakukan secara manual dengan memberikan pakan secukupnya.

\section{Minggu Kedua}

Pada minggu kedua dimulai dari hari kamis, 4 Juli 2019 sampai dengan hari rabu, 10 Juli 2019. Dari hasil tabel pengamatan minggu pertama dapat dilihat pada lampiran bahwa hampir semua komponen dapat bekerja dengan baik kecuali modul GSM yang hanya beberapa saja tidak dapat mengirimkan SMS pada handphone pengguna, seperti pada hari pertama jam 9 pagi, hari ke tiga pada jam 9 malam, pada hari ke 5 pada jam 9 pagi dan malam, hari ketujuh pada jam 9 pagi dan 9 malam. Pada pengujian tersebut bahwa hanya terdapat 6 waktu yang tidak dapat mengirimkan SMS.

$$
\text { SMS Error }={ }^{21-15} \quad 100 \%=28,57 \%
$$

\section{Minggu Ketiga}

Pada minggu ketiga dimulai dari hari kamis,11 Juli 2019 sampai dengan hari rabu, 17 Juli 2019. Dari hasil tabel pengamatan minggu kedua dapat dilihat pada lampiran bahwa hampir semua komponen dapat bekerja dengan baik kecuali modul GSM yang hanya beberapa saja tidak dapat mengirimkan SMS pada handphone pengguna, seperti pada hari pertama dan kedua masing masing terdapat 3 waktu, hari ke tiga pada jam 9 pagi, pada hari ke 5 pada jam 9 malam, hari ketujuh pada jam 9 pagi. Pada pengujian tersebut bahwa hanya terdapat 9 waktu yang tidak dapat mengirimkan SMS.

SMS Error $=\frac{21-12}{21} \quad 100 \%=42,85 \%$

\section{d. Pengamatan Perkembangan Ikan}

Pada pengamatan ini kita mengetahui perkembangan berat ikan dengan memberikan pakan secara bertahap yaitu 3 kali sehari. Hal yang kemudian dilakukan adalah menetapkan jumlah ikan dan berat ikan. Lalu menghitung jumlah pakan yang keluar dalam sehari dibagi menjadi tiga waktu, yaitu pada jam 9 pagi, jam 3 sore, dan jam 9 malam.

Tabel 11 Perkembangan Ikan

\begin{tabular}{ccccc}
\hline No & $\begin{array}{c}\text { Percobaan } \\
\text { Perminggu }\end{array}$ & $\begin{array}{c}\text { Jumlah } \\
\text { Ikan }\end{array}$ & $\begin{array}{c}\text { Berat Ikan } \\
\text { total (gram) }\end{array}$ & $\begin{array}{c}\text { Berat satu } \\
\text { ekor ikan } \\
\text { (gram) }\end{array}$ \\
& & & \\
\hline
\end{tabular}

$\begin{array}{llccc}\text { 1. } & \text { Berat awal } & 31 & 98 & 3,16 \\ \text { 2. } & \text { Minggu Pertama } & 31 & 130 & 4,19 \\ \text { 3. } & \text { Minggu Kedua } & 30 & 174 & 5,8 \\ \text { 4. } & \text { Minggu Ketiga } & 29 & 195 & 6,72\end{array}$

Pengujian dilakukan dari berat awal ikan sebesar 3,16gr perekor, berat minggu pertama sebesar $4,19 \mathrm{gr}$ perekor, berat minggu kedua sebesar 5,8gr perekor, berat minggu ketiga sebesar $6,72 \mathrm{gr}$ perekor.

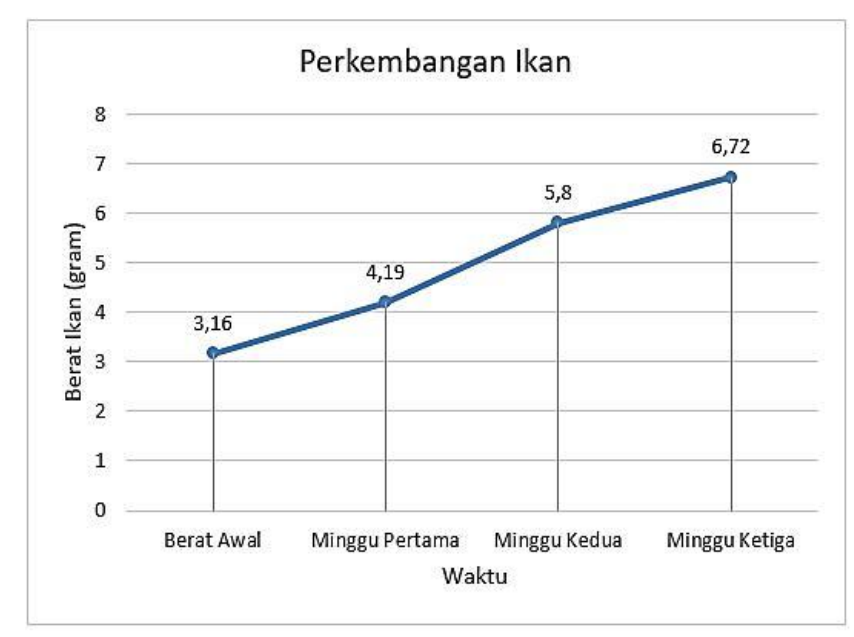

Gambar 19 Grafik Perkembangan Ikan

Dari gambar grafik 4.15 tersebut dapat dilihat bahwa perkembangan ikan lele perekor meningkat pada minggu pertama sebesar 1,03gr, minggu kedua meningkat sebesar $1,61 \mathrm{gr}$ dan pada minggu ketiga meningkat sebesar $0,92 \mathrm{gr}$

\section{Kesimpulan}

Berdasarkan dari hasil pengujian dan pengambilan data pada Perancangan Pakan Ikan otomatis maka dapat disimpulkan bahwa pada perancangan pakan ikan otomatis ini, dalam pengujian modul gsm terdapat kesalahan sms yang tidak terkirim pada percobaan minggu kedua sebesar $28,57 \%$ dan pada percobaan minggu ketiga sebesar $42,85 \%$. Berdasarkan hasil pengujian pakan ikan yang keluar dari wadahnya didapat $0 \%$ error atau kesalahan. Hasil pengujian pakan ikan yang keluar dari wadah pada percobaan minggu kedua kesalahan atau error yang terjadi sebesar 1,06\% dan pada percobaan minggu ketiga kesalahan atau error yang terjadi sebesar 3,57\%. Lalu wadah pakan dapat terdeteksi habis apabila makanannya tersisa sebesar 20,5gr. Kemudian pada perancangan pakan ikan otomatis ini dilakukan pengujian waktu RTC dengan waktu komputer dan didapat bahwa waktu RTC lebih cepat dibandingkan dengan waktu komputer. 


\section{Penghargaan}

Dalam penyusunan makalah ini, tidak terlepas dari bantuan, bimbingan, dukungan dan doa yang tulus dari banyak pihak, dari masa perkuliahan sampai pada penyusunan skripsi ini. Tanpa itu semua sangatlah sulit bagi penulis untuk menyelesaikan skripsi ini. Oleh karena itu, dalam kesempatan ini penulis dengan ingin menyampaikan terima kasih yang setulus-tulusnya kepada:

1. Ayahanda tercinta Supandi dan Ibunda tercinta Asmah selaku orang tua yang tiada henti memberikan doa serta dukungan baik moril maupun materil bagi penulis.

2. Dwi Astuti Cahyasiwi, ST., MT dan M. Mujirudin, S.T., M.T selaku pembimbing II yang tidak pernah lelah mebimbing penulis dalam segala hal, baik dalam ilmu pengetahuan, nasehat serta motivasi sehingga penulis mampu menyelesaikan tugas akhir ini.

3. Dr. Sugema, S.T., M.Kom selaku Dekan Fakultas Teknik Universitas Muhammadiyah Prof. DR.

\section{HAMKA.}

4. Harry Ramza, S.T., M.T., Ph.D selaku Kaprodi Teknik Elektro yang telah mewakili orang tua dalam hal pendidikan dan pembimbing akademik dikampus Fakultas Teknik Universitas Muhammadiyah Prof. DR. HAMKA.

5. Seluruh dosen Teknik Elektro UHAMKA yang tidak dapat disebutkan satu persatu atas ilmu dan bimbingannya yang telah diberikan selama menempuh pendidikan.

6. Seluruh teman-teman Teknik Elektro angkatan 2015 serta seluruh kawan-kawan Fakultas Teknik UHAMKA dan semua pihak yang telah membantu penulis dalam menyelesaikan skripsi ini, yang tidak dapat disebutkan satu persatu.

\section{Kepustakaan}

[1] Direktorat Jendral Perikanan Budidaya, "Capaian Kinerja Subsektor Perikanan Budidaya dan Outlook," Kementerian Kelautan dan Perikanan, Jakarta, 2018.

[2] L. Nulhakim, Alat Pemberi Makan Ikan di Akuarium Otomatis Berbasis Mikrokontroler ATMEGA16, Yogyakarta: Program Studi Teknik Elektro, Universitas Negeri Yogyakarta, 2014.

[3] A. R. Saragih, Rancang Bangun Perangkat Pemberi Pakan Ikan Otomatis Pada kolam Pembenihan Ikan Berbasis Arduino, Tanjung Pinang: Program Studi Teknik Elektro, Universitas Maritim Raja Ali Haji, 2016.

[4] H. Santoso, "Panduan Praktis Arduino untuk Pemula," dalam Vol.1, Trenggalek, www.elangsakti.com, 2015, p. 1.

[5] A. Risal, Mikrokontroller dan Interface, Makassar: Universitas Negeri Makassar, 2017.

[6] A. Octavianto, Perancangan Lengan Robot, Jakarta: Program Studi Teknik Elektro, Universitas Muhammadiyah Prof. DR. HAMKA, 2018. 